\title{
Predialysis therapeutic care and health-related quality of life at dialysis onset (The pharmacoepidemiologic AVENIR study)
}

\author{
Stephanie Boini ${ }^{1,2^{*}}$, Luc Frimat ${ }^{2,3}$, Michele Kessler ${ }^{3}$, Serge Briançon ${ }^{1,2}$, Nathalie Thilly ${ }^{1,2}$
}

\begin{abstract}
Background: To determine the impact of the quality of pre-dialysis nephrological care on health-related quality of life (HRQOL) at dialysis onset, which has not been well evaluated.

Methods: All adults who began a dialysis treatment in the administrative region of Lorraine (France) in 2005 or 2006, were enrolled in this prospective observational study.

HRQoL was measured using the Kidney Disease Quality of Life V36 questionnaire, which enables calculation of two generic (physical and mental) and three specific dimensions (Symptoms/problems, Effects and Burden of kidney disease). The specific dimensions were scored from 0 to 100 (worst to best possible functioning). Pre-dialysis nephrological care was measured using three indicators: quality of therapeutic practices (evaluated across five main aspects: hypertension/proteinuria, anemia, bone disease, metabolic acidosis and dyslipidemia), time since referral to a nephrologist and number of nephrology consultations in the year preceding dialysis treatment.

Results: Two thousand and eighty-three (67.4\%) patients were referred to a nephrologist more than 1 month before dialysis initiation and completed the HRQoL questionnaire. Quality of therapeutic practices was significantly associated with the Mental component. Time since referral to a nephrologist was associated with Symptoms/ problems and the Effects of kidney disease dimensions, but no relationship was found between the number of nephrology consultations and HRQoL.
\end{abstract}

Conclusions: HRQoL at dialysis onset is significantly influenced by the quality of pre-dialysis nephrological care. Therefore, disease management should be emphasized.

\section{Background}

Although the correlation between chronic kidney disease (CKD) and risk of cardiovascular morbidity and mortality has been thoroughly investigated, studies evaluating the impact of CKD on health-related quality of life (HRQOL) are somewhat scarce [1-3]. In particular, the relationship between quality of pre-dialysis care and HRQoL at dialysis onset has not been investigated to date. However, numerous studies have shown associations between quality of pre-dialysis care and dialysis mortality on one hand [4] and, HRQoL at dialysis onset and dialysis mortality on the other hand [5-7].

\footnotetext{
* Correspondence: sboini@free.fr

${ }^{1}$ Clinical Epidemiology and Evaluation, CIC-EC CIE6 Inserm, University hospital of Nancy, France

Full list of author information is available at the end of the article
}

The quality of pre-dialysis care is a multidimensional concept that includes several aspects, for example, clinical follow-up by nephrologists, the quality of therapeutic care, the quality of dialysis preparation, and counselling.

A positive association between early referral to a nephrologist and survival after starting renal replacement therapy (RRT) has been clearly demonstrated [8] but the impact of early referral on HRQoL at initiation of dialysis is still a matter for debate [2,9]. Moreover, the lack of a consensus over the definition of 'early' and 'late' nephrology referral has left primary care providers unsure about the optimum timing and pattern of nephrology care. Nephrological care was recently assessed from a quantitative rather than a qualitative perspective, focusing on the number of nephrology consultations before RRT [10]. Moreover, a favourable association between early referral or a high number of

\section{() Biomed Central}


pre-ESRD nephrology consultations and quality of therapeutic care has been suggested $[11,12]$. Likewise, quality of pre-ESRD therapeutic practices has been found to be associated with survival after RRT [4].

We used data from the pharmacoepidemiologic AVENIR (AVantagE de la Néphroprotection dans l'Insuffisance Rénale) study to explore the impact on HRQoL at dialysis onset of three pre-dialysis indicators of quality of care: quality of therapeutic practices, time since referral to a nephrologist and number of nephrology consultations during the year preceding dialysis. Our hypothesis is that the higher the quality of pre-dialysis care, the better the HRQoL. Our aim is to heighten nephrologists' awareness of the outstanding importance of the quality of pre-dialysis care.

\section{Methods}

\section{Setting, study design and sample selection}

The AVENIR study was an observational cohort study involving 12 private and public nephrology units operating in the administrative region of Lorraine, northeast France (population of 2,339,000, according to the 2006 census). Its methodology was approved by the ethics committee of the regional university hospital and is described in detail elsewhere [11].

All adults with CKD who began a dialysis treatment in one of the 12 units between January 1, 2005, and December 31, 2006, were identified from the regional ESRD registry (REIN registry) and enrolled in the AVENIR study. Patients with reversible renal failure and those returning to dialysis following kidney graft failure were not included. The present analysis focuses on the impact of several features of pre-dialysis nephrological care on HRQoL of ESRD patients referred to a nephrologist at least 1 month before the start of dialysis.

\section{Data collection and definitions}

A standardized form was used to retrospectively collect demographic, clinical, biological and therapeutic data from outpatient medical records. Demographic and clinical data (except for blood pressure) were from inclusion in the REIN registry. Blood pressure readings, as well as biological and therapeutic data covered the observation period from the day of the first nephrology consultation to dialysis onset, and were used to evaluate the quality of therapeutic practices. Demographic and clinical variables used as adjustment factors in the analysis included age, gender, body mass index (BMI), primary renal disease and the presence (or absence) of at least one co-morbidity. BMI was calculated as weight $(\mathrm{kg}) / \mathrm{square}$ of height $(\mathrm{m})$. Primary renal disease was categorized into five groups: glomerulonephritis, diabetic or hypertensive nephropathy, hereditary nephropathy and others. Co-morbidity was defined as the presence of clinically significant non-renal disease (e.g. cardiac disease, vascular disease, respiratory disease, diabetes mellitus and malignancy).

In addition, all patients who began a dialysis treatment had to complete a HRQoL questionnaire as soon as possible after their first session, and within the first 3 months of replacement therapy.

\section{Quality of therapeutic practices}

The appropriateness of pre-dialysis therapeutic practices was assessed in terms of adherence to current guidelines [13-17] covering five main aspects of therapeutic care in CKD: hypertension/proteinuria, anemia, bone disease, metabolic acidosis and dyslipidemia. A practice was considered inappropriate if one treatment was not prescribed when it was indicated for a biological or clinical reason; otherwise, the practice was considered appropriate (Table 1). For example, hypertensive care was recorded as inappropriate for a patient not given antihypertensive medication when his or her mean blood pressure during the observation period was $>130 / 80 \mathrm{mmHg}$. More detailed information has been published elsewhere [11].

The quality of therapeutic practices was then estimated for each patient in terms of the number of aspects (out of the five above) being managed appropriately. Quality of practices was considered to be High when four or five aspects were appropriately managed, Moderate when including two or three aspects and finally Poor when none or just one aspect was appropriately managed.

\section{Pre-dialysis nephrology care}

Pre-dialysis nephrology care was assessed in terms of the timing of referral to a nephrologist before dialysis onset and the number of nephrology consultations during the year preceding dialysis treatment.

Patients were classified into three groups according to their timing of referral to a nephrologist as follows: more than 12 months before dialysis onset (early referral), less than 12 months and more than 4 months (intermediate referral), and less than 4 months and more than 1 month (late referral). The number of nephrology consultations during the year preceding dialysis was categorized into three groups: 0 to 2 consultations, 3 to 5 consultations, and 6 consultations or more.

\section{Outcome of interest}

HRQoL was measured with the French version of the 'Kidney Disease Quality of Life' (KDQoL) V36 questionnaire [18]. This instrument includes a 12-item health survey as the generic core (SF12), supplemented with multi-item scales targeted at particular concerns of patients with kidney disease and on dialysis. 
Table 1 Definition of 'Inappropriate therapeutic care' and percentage of patients being managed appropriately by therapeutic aspect evaluated ( $n=420$ included) [10]

\begin{tabular}{|c|c|c|}
\hline $\begin{array}{l}\text { Therapeutic fields } \\
\text { evaluated }\end{array}$ & Definition of 'Inappropriate therapeutic care' & $\begin{array}{l}\% \text { of patients being managed } \\
\text { appropriately }\end{array}$ \\
\hline \multirow{2}{*}{$\begin{array}{l}\text { Hypertension/ } \\
\text { Proteinuria }\end{array}$} & Mean $\mathrm{BP}^{\mathrm{a}}>130 / 80 \mathrm{mmHg}$ without prescription of an antihypertensive agent & 72.4 \\
\hline & Mean proteinuria $>0.5 \mathrm{~g} / \mathrm{dl}$ without prescription of a renin-angiotensin system inhibitor & \\
\hline \multirow[t]{4}{*}{ Anemia } & $\begin{array}{c}\text { Hemoglobin }<11 \mathrm{~g} / \mathrm{dl} \text { in two successive readings without prescription of an } \\
\text { erythropoiesis-stimulating agent }\end{array}$ & \\
\hline & Erythropoiesis-stimulating therapy without prescription of iron & 56.2 \\
\hline & Or & \\
\hline & $\begin{array}{c}\text { Mean serum ferritin }<100 \mathrm{ng} / \mathrm{ml} \text { without prescription of iron (in patients not given } \\
\text { erythropoiesis-stimulating therapy) }\end{array}$ & \\
\hline \multirow[t]{4}{*}{ Bone disease } & Mean serum calcium $<10.2 \mathrm{mg} / \mathrm{dl}$ without prescription of calcium & 16.7 \\
\hline & Mean serum 25 -hydroxyvitamin $D<30 \mathrm{ng} / \mathrm{ml}$ without prescription of ergocalciferol & \\
\hline & Or & \\
\hline & $\begin{array}{c}\text { Mean serum 25-hydroxyvitamin } \mathrm{D}>30 \mathrm{ng} / \mathrm{ml} \text { and hyperparathyroidism without } \\
\text { prescription of alfacalcidol }\end{array}$ & \\
\hline Metabolic acidosis & Mean serum bicarbonates $<23 \mathrm{mEq} / \mathrm{l}$ without prescription of bicarbonate & 60.2 \\
\hline Dyslipidemia & $\begin{array}{c}\text { Mean fasting total cholesterol }>201 \mathrm{mg} / \mathrm{dl} \text { or mean triglycerides }>150.5 \mathrm{mg} / \mathrm{dl} \text { without } \\
\text { prescription of a lipid-lowering therapy }\end{array}$ & 61.4 \\
\hline
\end{tabular}

${ }^{\mathrm{a}} \mathrm{BP}$, blood pressure.

The 12 items of SF12 - a shorter version of the generic SF36 instrument - may be combined into two summary measures: Physical (PCS12) and Mental (MCS12) Component Summary Scales [19]. They are computed to have means of 50 and standard deviations of 10 in a general US population. The specific items may be summarized into three dimensions: symptoms/problems (12 items), effects of kidney disease on daily life (8 items), and burden of kidney disease (4 items) [20]. All these specific dimensions, scored from 0 to 100 (worst to best possible functioning), are calculated as the mean of item values when no more than half of the items are missing. Otherwise, scores are recorded as missing.

We calculated the Cronbach coefficient of the three specific dimensions, confirming their internal consistency in our sample $(0.76,0.77$ and 0.79 for Symptoms, Effects and Burden dimensions, respectively).

\section{Statistical Analysis}

Descriptive statistics were used to assess patients' characteristics according to whether or not they had completed the KDQoL questionnaire (respondents/non-respondents). Continuous variables are presented as means \pm standard deviations and categorical variables as percentages. Comparisons between respondents and non-respondents were made using the Pearson $\mathrm{Chi}^{2}$ test and analysis of variance for categorical and continuous variables, respectively.

Analysis of variance models were used to explore the impact of the three pre-dialysis indicators defined above on each HRQoL score at dialysis onset in a bivariable analysis. Indicators significantly associated with HRQoL in the bivariable analysis were then candidates in a multivariable analysis of variance model, adjusted for the main patient characteristics known to be associated with HRQoL in CKD (age, gender, BMI, primary renal disease, co-morbidity) [21-24] and the nephrology unit. The HRQoL scores are reported as means \pm standard errors and $P$-value. A $P$-value of $<0.05$ for two-sided tests was considered significant. All analyses were performed with SAS version 9.1 (SAS Institute, Inc., Cary, N.C).

\section{Results}

\section{Patient characteristics}

On the 566 patients enrolled in the AVENIR study, 420 were referred to a nephrologist more than 1 month before dialysis initiation and are considered here. Among them, 137 did not complete the KDQoL questionnaire at all $(\mathrm{n}=99)$ or completed it after the third month of dialysis treatment $(\mathrm{n}=38)$. Thus, 283 patients completed the KDQoL questionnaire as indicated and were considered as respondents (response rate $=67.4 \%$ ).

Table 2 shows the characteristics of included patients overall $(\mathrm{n}=420)$ and by respondent status. Among respondent patients, the mean age was $67.1 \pm 14.6$ years, and $63.3 \%$ were male. Hypertension and diabetes were the leading causes of CKD, and $44.2 \%$ of respondents had at least one co-morbidity. The average length of pre-dialysis nephrological care was $43.0 \pm 51.9$ months, and nearly half of these patients received between 3 and 5 nephrology consultations during the year preceding dialysis.

As compared with non-respondents, respondents were younger $(P=0.03)$. They also tended to have more pre-dialysis nephrology consultations and were more likely to be referred early to a nephrologist than non- 
Table 2 Characteristics of included patients according to their respondent status

\begin{tabular}{|c|c|c|c|c|}
\hline & \multirow{2}{*}{$\begin{array}{c}\text { Overall } \\
(\mathrm{N}=420)\end{array}$} & \multicolumn{3}{|c|}{ Respondents } \\
\hline & & $\begin{array}{c}\text { YES } \\
(\mathrm{N}=283)\end{array}$ & $\begin{array}{c}N O \\
(N=137)\end{array}$ & $P$ \\
\hline Male sex (\%) & 61.0 & 63.3 & 56.2 & 0.17 \\
\hline \multicolumn{5}{|l|}{ Age at dialysis onset, year } \\
\hline$m \pm S D$ & $68.2 \pm 14.8$ & $67.1 \pm 14.6$ & $70.5 \pm 15.1$ & 0.03 \\
\hline$<45(\%)$ & 8.6 & 9.2 & 7.3 & 0.06 \\
\hline $45-64(\%)$ & 23.8 & 26.9 & 17.5 & \\
\hline$\geq 65(\%)$ & 67.6 & 64.0 & 75.2 & \\
\hline $\begin{array}{l}\text { Body mass index } \geq 25 \\
\mathrm{~kg} / \mathrm{m}^{2}(\%)\end{array}$ & 59.8 & 60.8 & 57.7 & 0.55 \\
\hline \multicolumn{5}{|l|}{ Primary renal disease (\%) } \\
\hline Glomerulonephritis & 10.3 & 11.3 & 8.1 & 0.55 \\
\hline $\begin{array}{l}\text { Diabetic } \\
\text { nephropathy }\end{array}$ & 22.7 & 20.5 & 27.2 & \\
\hline $\begin{array}{l}\text { Hypertensive } \\
\text { nephropathy }\end{array}$ & 23.6 & 24.4 & 22.1 & \\
\hline $\begin{array}{l}\text { Hereditary } \\
\text { nephropathy }\end{array}$ & 5.5 & 5.7 & 5.7 & \\
\hline Others & 37.9 & 38.2 & 37.5 & \\
\hline Comorbid condition (\%) & 47.1 & 44.2 & 53.3 & 0.08 \\
\hline \multicolumn{5}{|l|}{$\begin{array}{l}\text { Quality of therapeutic } \\
\text { practices (\%) }\end{array}$} \\
\hline High & 22.1 & 23.7 & 19.0 & 0.12 \\
\hline Moderate & 65.7 & 62.5 & 72.3 & \\
\hline Poor & 12.1 & 13.8 & 8.8 & \\
\hline \multicolumn{5}{|l|}{$\begin{array}{l}\text { Time since referral to a } \\
\text { nephrologist, months }\end{array}$} \\
\hline $\mathrm{m} \pm \mathrm{SD}$ & $42.0 \pm 52.3$ & $43.0 \pm 51.9$ & $39.9 \pm 53.2$ & 0.57 \\
\hline$>12(\%)$ & 69.3 & 72.8 & 62.0 & 0.07 \\
\hline$[4-12[(\%)$ & 17.9 & 16.3 & 21.2 & \\
\hline$[1-4[(\%)$ & 12.9 & 11.0 & 16.8 & \\
\hline \multicolumn{5}{|l|}{$\begin{array}{l}\text { Number of nephrology } \\
\text { consultations (\%) }\end{array}$} \\
\hline 6 or more & 24.6 & 28.0 & 17.5 & 0.06 \\
\hline $3-5$ & 49.2 & 47.2 & 53.3 & \\
\hline $0-2$ & 26.3 & 24.8 & 29.2 & \\
\hline
\end{tabular}

respondents, but these differences did not reach significance.

\section{HRQoL results}

Table 3 shows that HRQoL measured by the SF12 was altered in its physical (PCS12) and mental (MCS12) components: respectively -10.5 and -7.1 points, as compared with the general US population and -10.8 and -4.3 points, as compared with the general French population [25]. The specific scores varied from 41.1 points for the dimension 'Burden of kidney disease' to 67.9 points for 'Symptoms/problems'.

\section{Impact of quality of therapeutic practices and pre-dialysis nephrology care on HRQoL}

Table 4 presents HRQoL scores for pre-dialysis indicators that were significantly associated with HRQoL dimensions in the multivariable analysis. The Physical Component was influenced by none of the three predialysis indicators. Quality of therapeutic practices was significantly associated with the Mental Component: the higher the quality of practices, the better the MCS12 score (High quality vs. Poor $=+3.8$ points, $P=0.01$ ). Time since referral to a nephrologist was associated with two specific dimensions: 'Symptoms/problems' and 'Effects of kidney disease'. The longer the pre-dialysis nephrological follow-up, the better the score related to 'Symptoms/problems' ( $>12$ months $v s .1$ to 4 months = +10.9 points, $P=0.001$, and $4-12$ months vs. 1 to 4 months $=+10.5$ points, $\mathrm{P}=0.007)$ and the better the score of 'Effects of kidney disease' ( $>12$ months vs. 1 to 4 months $=+8.4$ points, $P=0.03)$. The number of nephrology consultations during the year preceding dialysis was associated with none of the five dimensions of HRQoL.

When limiting the analyses to subjects who completed the HRQoL questionnaire within 30 days after dialysis onset ( $n=211$ ), all the previously observed associations remained statistically significant. Results remained unchanged too when analyses were re-run with only subjects who completed the questionnaire within the first 10 days after dialysis onset $(n=120)$.

\section{Discussion}

To our knowledge, this observational study is the first to explore in depth the association between the quality of pre-ESRD nephrological care, evaluated across three indicators, and HRQoL at dialysis onset. In a field where randomized controlled studies cannot be ethically designed, our results suggest: first, a mild, but

Table 3 HRQoL scores at dialysis initiation ( $N=283$ respondents)

\begin{tabular}{lccc}
\hline HRQoL scores & N & Mean & Standard Error \\
\hline Physical (PCS12) & 248 & 39.5 & 5.8 \\
Mental (MCS12) & 248 & 42.9 & 7.0 \\
Symptoms/problems & 278 & 67.9 & 16.8 \\
Effects of kidney disease & 280 & 61.2 & 20.3 \\
Burden of kidney disease & 278 & 41.1 & 23.6 \\
\hline
\end{tabular}

Abbreviations: $\mathrm{HRQ}$ L, health related quality of life; PCS, physical component summary; MCS, mental component summary. 
Table 4 Impact of quality of therapeutic practices and pre-dialysis nephrology care on HRQoL ( $N=283$ respondents)

\begin{tabular}{|c|c|c|c|c|c|c|c|c|c|c|c|c|c|c|c|}
\hline & \multicolumn{3}{|c|}{ PCS12 } & \multicolumn{3}{|c|}{ MCS12 } & \multicolumn{3}{|c|}{$\begin{array}{l}\text { Symptoms/ } \\
\text { problems }\end{array}$} & \multicolumn{3}{|c|}{$\begin{array}{l}\text { Effects of kidney } \\
\text { disease }\end{array}$} & \multicolumn{3}{|c|}{$\begin{array}{c}\text { Burden of kidney } \\
\text { disease }\end{array}$} \\
\hline & Mean* & SE & $P$ & Mean* & SE & $P$ & Mean* & SE & $P$ & Mean* & SE & $P$ & Mean* & SE & $P$ \\
\hline Quality of therapeutic practices & 0.006 & 0.006 & NS & & & 0.05 & & & NS & & & NS & & & NS \\
\hline High & & & & 44.6 & 1.0 & 0.01 & & & & & & & & & \\
\hline Moderate & & & & 42.8 & 0.7 & 0.13 & & & & & & & & & \\
\hline Poor & & & & 40.8 & 1.3 & ref. & & & & & & & & & \\
\hline Time since referral to a nephrologist & & & NS & & & NS & & & 0.004 & & & 0.09 & & & NS \\
\hline$>12$ months & & & & & & & 69.9 & 1.5 & 0.001 & 63.5 & 1.8 & 0.03 & & & \\
\hline$[4-12]$ & & & & & & & 69.5 & 2.7 & 0.007 & 62.9 & 3.2 & 0.09 & & & \\
\hline$[1-4]$ & & & & & & & 59.0 & 3.2 & ref. & 55.1 & 3.9 & ref. & & & \\
\hline Number of nephrology consultations & & & NS & & & NS & & & NS & & & NS & & & NS \\
\hline \multicolumn{16}{|l|}{6 or more } \\
\hline \multicolumn{16}{|l|}{$3-5$} \\
\hline $0-2$ & & & & & & & & & & & & & & & \\
\hline
\end{tabular}

Abbreviations: HRQoL, health related quality of life; PCS, physical component summary; MCS, mental component summary; SE, standard error; NS, not significant. *Model adjusted for age, gender, BMI, primary renal disease, presence of co-morbidity, and nephrology unit.

statistically significant, association between quality of therapeutic practices, evaluated across five therapeutic aspects, and mental, but not physical, quality of life; second, the earlier the referral to a nephrologist, the better the control of symptoms, problems and effects of CKD; third, a lack of association between the number of nephrology consultations and HRQoL.

HRQoL was measured with the validated French version of the KDQoL V36 [20]. The two generic scores allowed ESRD patients to be compared with the general population, whereas the three specific scores explored the impact of the kidney disease on daily life. Both physical and mental summary scores were well below 50, which is the expected average from the US general population. These results are consistent with previous studies [1,7]. Moreover, HRQoL at dialysis onset was altered compared to the French general population, particularly the physical component [25]. Disease-specific scores observed in our ESRD sample were close to scores reported by Molsted et al [26], but well below than those observed by Mujais et al [27] in their CKD stage V patients. Nevertheless, in this last study, HRQoL was measured when patients were not yet under dialysis treatment, which seems to have a marked impact on the specific dimensions of HRQoL, particularly the 'Burden of kidney disease'. In any case, this dimension was always the most impaired HRQoL dimension in CKD or ESRD patients. This emphasises the need for psychological support of ESRD patients at dialysis onset.

Previous studies using the SF36 suggest that scores in the range of 2 or 3 points on the physical and mental summary scores (equivalent to 0.2 to $0.3 \mathrm{SD}$ ) are likely to be clinically important [28]. We observed, in the MCS12 score, differences according to the level of quality of therapeutic practices that were around 2 to 4 points, suggesting that they are likely to be noticeable and meaningful to patients at dialysis initiation. As perceived mental health is an independent predictor of mortality and morbidity [7], attaining the target of MCS12 score observed in patients with high quality of therapeutic practices is of interest. No other study to date has investigated the impact of the quality of preESRD therapeutic practices on HRQoL at dialysis initiation.

Concerning the impact of time since referral to a nephrologist on HRQoL, results from previous studies are conflicting [1,9]. Sesso and Yoshihiro [9] have demonstrated that patients referred late to a nephrologist ( $\leq$ one month before starting dialysis) have significantly worse HRQoL than those referred early $(\geq 6$ months). We found similar tendencies in two of the three specific HRQoL dimensions (symptoms and effects) but no comparison can be made in HRQoL scores because Sesso and Yoshihiro used another quality of life questionnaire (Kidney Disease Questionnaire). These associations we found between time referral to a nephrologist and specific dimensions of HRQoL may reflect the benefit of the nephrologist's having had more time to evaluate and treat properly somatic symptoms and consequences of CKD on his patients. Conversely, Caskey et al found no significant difference between early and late referral patients in any of the SF36 summary scores or domain scores [1]. However, in this study, patients were considered 'early referred' if they 
had been followed by a nephrologist for $>1$ month before their first dialysis. As we considered early referred patients those who had been followed for more than 12 months before dialysis onset, the results are not comparable. The main difficulty in comparing results of studies investigating the time of referral to a nephrologist is the use of multiple definitions of 'early' and 'late'.

Another way of assessing pre-ESRD nephrological care is to consider the frequency of nephrology consultations before RRT rather than timing of referral [10]. In our study, we found no association between the number of nephrology consultations during the year preceding RRT and HRQoL at initiation of dialysis. Studies published to date have investigated the relationship between the frequency of patient-nephrologist visits during maintenance dialysis and HRQoL $[10,29]$ but none has looked at the impact on HRQoL of frequency of visits before RRT. Moreover, neither Plantinga et al [10] nor Mentari et al [29] found any association between the frequency of patient-nephrologist contact and HRQoL of dialyzed patients.

Some possible limitations should be considered when interpreting our findings. First, as this study was observational, it allows us to measure associations between pre-dialysis indicators and HRQoL, but cannot demonstrate strictly causal relationships. However, given that a controlled trial in which patients would be randomized on quality of pre-dialysis care is clearly impractical for ethical reasons, our study is of value. Second, almost one third of included patients did not complete the HRQoL questionnaire. Nevertheless, given the relatively minor differences (only age) between respondents and non-respondents, we can assume that these nonresponses probably did not introduce a systematic bias that would distort our conclusions. Third, HRQoL was measured up to three months after the start of dialysis. This may reflect care received on dialysis as much as pre-dialysis care, but sensitivity analyses including only patients who completed the HRQoL within the first 10 days after the dialysis onset did not change the results. Fourth, despite adjustment for the main patient characteristics known to be associated with HRQoL in CKD, residual confounding due to the lack of data on variables - such as socioeconomics parameters - for which we could not account may still exist. Fifth, several aspects of quality of pre-dialysis care were taken into account in our study, but not all. For example, the quality of dialysis preparation and counseling was not considered here.

Concerning management of CKD, clinicians have always recognized the importance of diagnosing functional impairments. Our study provides finally an accurate measure of patient-perceived health status at dialysis onset, and highlights the impact of quality of therapeutic practices and early nephrology referral on HRQoL, independently of the number of consultations.

\section{Conclusions}

To our knowledge, this observational study is the first to explore the association between the quality of pre-ESRD nephrological care and HRQoL at dialysis onset. The mental component, but not the physical, is significantly influenced by the quality of pre-dialysis nephrological care, evaluated across five therapeutic aspects. Late referral to a nephrologist is associated with poor HRQoL (symptoms/problems and effects of disease dimensions). Therefore, CKD disease management incorporating psychological support should be emphasized.

\section{Acknowledgements}

The authors would like to thank the patients, nephrologists and medical directors of the participating hospitals in Lorraine.

The AVENIR study was supported by a grant from the Hospital Program of Clinical Research (PHRC 2004) of the French Ministry of Health.

\section{Author details}

${ }^{1}$ Clinical Epidemiology and Evaluation, CIC-EC CIE6 Inserm, University hospital of Nancy, France. ${ }^{2}$ Nancy University, P. Verlaine - Metz University, Paris - Descartes University, EA 4360 Apemac, Nancy, France. ${ }^{3}$ Nephrology, University hospital of Nancy, France.

\section{Authors' contributions}

SBo \& NT participated in the design of this ancillary work, reviewed the literature, performed the statistical analysis, and drafted the manuscript. LF participated in the design of this work and provided feedback on it. MK and $\mathrm{SBr}$ participated in the design and provided feedback. All authors collaborated interactively, and read and approved the final version.

\section{Competing interests}

The authors declare that they have no competing interests.

Received: 11 June 2010 Accepted: 24 January 2011

Published: 24 January 2011

\section{References}

1. Caskey FJ, Wordsworth S, Ben T, de Charro FT, Delcroix C, Dobronravov V, van Hamersvelt $H$, Henderson I, Kokolina $E$, Khan $\mathrm{IH}$, et al: Early referral and planned initiation of dialysis: what impact on quality of life? Nephrol Dial Transplant 2003, 18:1330-1338.

2. Lash JP, Wang X, Greene T, Gadegbeku CA, Hall Y, Jones K, Kusek JW, Sika M, Unruh M: Quality of life in the African American Study of Kidney Disease and Hypertension: effects of blood pressure management. Am J Kidney Dis 2006, 47:956-964.

3. Soni RK, Weisbord SD, Unruh ML: Health-related quality of life outcomes in chronic kidney disease. Curr Opin Nephrol Hypertens 2010, 19:153-159.

4. Thilly N, Boini S, Loos-Ayav C, Kessler M, Briancon S, Frimat L: Impact of Predialysis Therapeutic Practices on Patient Outcomes During the First Year of Dialysis: The Pharmacoepidemiologic AVENIR Study. Med Care 2010.

5. Mapes DL, Lopes AA, Satayathum S, McCullough KP, Goodkin DA, Locatelli F, Fukuhara S, Young EW, Kurokawa K, Saito A, et al: Health-related quality of life as a predictor of mortality and hospitalization: the Dialysis Outcomes and Practice Patterns Study (DOPPS). Kidney Int 2003, 64:339-349.

6. Han SS, Kim KW, Na KY, Chae DW, Kim YS, Kim S, Chin HJ: Quality of life and mortality from a nephrologist's view: a prospective observational study. BMC Nephrol 2009, 10:39.

7. Lopez RK, Garcia Lopez FJ, de Alvaro MF, Alonso J: Perceived mental health at the start of dialysis as a predictor of morbidity and mortality 
in patients with end-stage renal disease (CALVIDIA Study). Nephrol Dial Transplant 2004, 19:2347-2353.

8. Kessler M, Frimat L, Panescu V, Briancon S: Impact of nephrology referral on early and midterm outcomes in ESRD: EPidemiologie de I'Insuffisance REnale chronique terminale en Lorraine (EPIREL): results of a 2-year, prospective, community-based study. Am J Kidney Dis 2003, 42:474-485.

9. Sesso R, Yoshihiro MM: Time of diagnosis of chronic renal failure and assessment of quality of life in haemodialysis patients. Nephrol Dial Transplant 1997, 12:2111-2116.

10. Plantinga LC, Jaar BG, Fink NE, Sadler JH, Levin NW, Coresh J, Klag MJ, Powe NR: Frequency of patient-physician contact in chronic kidney disease care and achievement of clinical performance targets. Int I Qual Health Care 2005, 17:115-121.

11. Thilly N, Boini S, Kessler M, Briancon S, Frimat L: Chronic Kidney Disease: Appropriateness of therapeutic management and associated factors in the AVENIR study (AVantagE de la Néphroprotection dans I'Insuffisance Rénale). Journal of evaluation in clinical practice 2009, 15:121-128.

12. Thilly N, Boini S, Kessler M, Briancon S, Frimat L: Nephrology referral and appropriateness of therapeutic drug care in chronic kidney disease. J Nephrol 2006, 19:303-311.

13. National Kidney Foundation: $\mathrm{K} / \mathrm{DOQ}$ clinical practice guidelines on hypertension and antihypertensive agents in chronic kidney disease. Am J Kidney Dis 2004, 43:S1-290.

14. Locatelli F, Aljama P, Barany P, Canaud B, Carrera F, Eckardt KU, Horl WH, Macdougal IC, Macleod A, Wiecek A, et al: Revised European best practice guidelines for the management of anaemia in patients with chronic renal failure. Nephrol Dial Transplant 2004, 19(Suppl 2):ii1-47.

15. National Kidney Foundation: K/DOQI clinical practice guidelines for bone metabolism and disease in chronic kidney disease. Am J Kidney Dis 2003, 42:S1-201.

16. National Kidney Foundation: K/DOQI Clinical practice guidelines for nutrition in chronic renal failure. Am J Kidney Dis 2000, 35:S1-140.

17. National Kidney Foundation: K/DOQI Clinical practice guidelines for management of dyslipidemias in patients with kidney disease. Am J Kidney Dis 2003, 41:--91.

18. Hays RD, Kallich JD, Mapes DL, Coons SJ, Carter WB: Development of the kidney disease quality of life (KDQOL) instrument. Qual Life Res 1994, 3:329-338.

19. Gandek B, Ware JE, Aaronson NK, Apolone G, Bjorner JB, Brazier JE, Bullinger M, Kaasa S, Leplege A, Prieto $L$, et al: Cross-validation of item selection and scoring for the SF-12 Health Survey in nine countries: results from the IQOLA Project. International Quality of Life Assessment. J Clin Epidemiol 1998, 51:1171-1178.

20. Boini S, Leplege A, Loos AC, Francais P, Ecosse E, Briancon S: Measuring quality of life in end-stage renal disease. Transcultural adaptation and validation of the specific Kidney Disease Quality of Life questionnaire. Nephrol Ther 2007, 3:372-383.

21. Seica A, Segall L, Verzan C, Vaduva N, Madincea M, Rusoiu S, Cristea S, Stefan M, Serbanescu D, Morosanu P, et al: Factors affecting the quality of life of haemodialysis patients from Romania: a multicentric study. Nephrol Dial Transplant 2009, 24:626-629.

22. Unruh ML, Newman AB, Larive B, Dew MA, Miskulin DC, Greene $T$ Beddhu S, Rocco MV, Kusek JW, Meyer KB: The influence of age on changes in health-related quality of life over three years in a cohort undergoing hemodialysis. J Am Geriatr Soc 2008, 56:1608-1617.

23. Mucsi I, Kovacs AZ, Molnar MZ, Novak M: Co-morbidity and quality of life in chronic kidney disease patients. J Nephrol 2008, 21 (Suppl 13):S84-S91.

24. Johansen KL, Kutner NG, Young B, Chertow GM: Association of body size with health status in patients beginning dialysis. Am J Clin Nutr 2006, 83:543-549.

25. INSEE. Présentation de l'enquête décennale de santé 2002-2003. [http:// www.insee.fr.ffr/publications-et-services], Accessed July 25, 2009.

26. Molsted S, Prescott L, Heaf J, Eidemak I: Assessment and clinical aspects of health-related quality of life in dialysis patients and patients with chronic kidney disease. Nephron Clin Pract 2007, 106:c24-c33.

27. Mujais SK, Story K, Brouillette J, Takano T, Soroka S, Franek C, Mendelssohn D, Finkelstein FO: Health-related quality of life in CKD Patients: correlates and evolution over time. Clin J Am Soc Nephrol 2009, 4:1293-1301.

28. Ware JE, Kosinski M, Keller SD: SF-36 Physical \& Mental Health Summary Scales: a user's manual. 5 edition. Boston, MA; 1994.
29. Mentari EK, DeOreo PB, O'Connor AS, Love TE, Ricanati ES, Sehgal AR: Changes in Medicare reimbursement and patient-nephrologist visits, quality of care, and health-related quality of life. Am J Kidney Dis 2005, 46:621-627.

doi:10.1186/1477-7525-9-7

Cite this article as: Boini et al:: Predialysis therapeutic care and healthrelated quality of life at dialysis onset (The pharmacoepidemiologic AVENIR study). Health and Quality of Life Outcomes 2011 9:7.

\section{Submit your next manuscript to BioMed Central and take full advantage of:}

- Convenient online submission

- Thorough peer review

- No space constraints or color figure charges

- Immediate publication on acceptance

- Inclusion in PubMed, CAS, Scopus and Google Scholar

- Research which is freely available for redistribution

Submit your manuscript at www.biomedcentral.com/submit
C Biomed Central 